\title{
Causal chain effects and turning points in young people's lives: a resilience perspective
}

\author{
Bruce Johnson and Sue Howard \\ University of South Australia, Australia
}

\section{Introduction}

In 1997, we began a research project that tracked a cohort of approximately 55 students aged between 9 and 12 years over a period of 5 years. The students lived in highly disadvantaged areas in Adelaide. Our aim was to identify the individual, social and environmental factors that contributed to each student's risk status and resilience and to track how this changed over time. By the end of the project the participants were aged from 13-16 years so we had been able to follow most of them through early adolescence and the often difficult transition from primary to high school. Our insights from the huge body of data thus gathered have been reported at Australian Association for Research in Education conferences from 1997 onwards, and in Australian and international refereed journals.

Many longitudinal studies, particularly in the areas of physical health and social adjustment (e.g., the Dunedin Multidisciplinary Health and Development study), have shown the benefits of tracking research participants beyond adolescence. Accordingly, we set about finding some of our former participants (aged now between 17 and 21) to ascertain their present risk and resilience status. In this paper, we draw on the work of Rutter (1999) to show, in two case studies, how negative and positive chain reactions influence people's lives and how key events, turning points or critical life choices disrupt these chain effects.

\section{Risk and resilience}

During the last century, much research attention was paid to studying risk in various populations. Many important longitudinal studies (e.g., the Dunedin Multidisciplinary Health and Developmental Study, and Canada's National Longitudinal Survey of Children and Youth) focused on the health of selected populations and were designed to track individuals over time to identify risk factors that predicted negative outcomes for individuals. While the principal focus for many 
studies was risk to health, when studying children and young people the term has often been used to predict vulnerability to other negative life outcomes, including school failure and/or dropping out of school, drug abuse, failed relationships, delinquency or criminal activities, unemployment, ill health and early death (Dryfoos, 1990; Hawkins et al., 1992; Rutter, 1980).

Out of these largely epidemiological, longitudinal studies an interesting finding emerged. As Bernard (1991) explains: 'Although a certain percentage of high risk children developed various problems, a greater percentage of children become healthy, competent young adults'. This finding opened the way for a new type of study in the 1980s and '90s. Rather than focusing on children who were the casualties of risk factors, some studies began to look at those children who did not develop problems despite being exposed to the same risks. In other words, these studies began to investigate what it was about these children and their circumstances that enabled them to achieve positive life outcomes despite exposure to risk. Instead of focusing on individual deficit, the new approach considered individual and community strengths. According to Masten et al. (1990), resilience is defined as the process of, capacity for, or outcome of, successful adaptation despite challenging or threatening circumstances.

The published research on resilience identifies both internal assets of the individual and external strengths in systems in which the individual grows and develops. Both are frequently referred to as protective factors (e.g., Garmezy, 1985; 1994; Rutter, 1987; Gore \& Eckenrode, 1994) or protective mechanisms (Rutter, 1987).

Commonly recognised internal protective factors are social competence, problem solving skills, mastery of basic numeracy and literacy skills, autonomy, and a sense of purpose and a future (see Masten et al., 1990; Gore \& Eckenrode, 1994; Consortium on the School-Based Promotion of Social Competence, 1994).

External assets or protective factors have been described in relation to three primary systems in the child's world: family, school and community. For the family, many of the protective factors uncovered by research are clearly associated with the consistency and quality of care and support the individual experiences during infancy, childhood and adolescence. The work of Rutter et al. (1979) shows that another source of external protection can be school. Children in discordant and disadvantaged homes are more likely to demonstrate resilient characteristics if they attend schools that have good academic records and attentive, caring teachers. Other studies have also shown the important role that teachers can play in resilient children's lives (Geary, 1988; Werner \& Smith, 1988; Coburn \& Nelson, 1989). Children in disadvantaged communities are generally considered more at risk than those in more affluent areas. However, certain community characteristics seem to be protective. The strength of social support networks provided by kin and social service agencies, for example, is one such factor (Pence, 1988). 


\section{The South Australian Longitudinal Study of Risk and Resilience}

In 1997 we began a study of the life experiences of at risk students who were judged to be displaying either resilient or non-resilient behaviour. This study differed from earlier studies in that it was qualitative rather than quantitative, Australian rather than British or American, and longitudinal. We began with 55 participants aged 912 years, 30 of whom were judged to be displaying non-resilient behaviour and 25 , resilient behaviour. Roughly equal numbers of boys and girls were originally recruited. Over the five years of the study, there was some attrition as children changed schools, moved away from the area and were unable to be contacted. Yet in 200130 of the original 55 participants could be contacted and were still interested in being part of the study. Each year, we asked the children the same questions which were designed to determine experiences which were clear life-stressors and factors that helped protect some of the children from negative outcomes. The interview protocol that we used was as follows:

1. What important things have happened to you since we last talked?

2. Who are the important people in your life now and why?

3. How do you like to spend your time these days?

4. What do you like about your life these days?

5. Have you done anything in the last four years that you are particularly proud of?

6. Have you any regrets about anything that has happened since we last spoke?

7. What are your plans for the future?

8. What do you think may help you achieve your plans?

9. What may stop you from achieving your plans?

10. What advice would you give other young people about life?

Analysis of the huge amount of data that such a long study produced gave us insights into the complex workings of children's lives in equally complex contexts. It was very clear that the risk or protective value of a factor depended on and was mediated by context. Thus, childhood disability, a risk factor noted by several studies, did not necessarily predict long-term negative outcomes if family and community support was strong. Conversely, a strong sense of self-esteem and selfefficacy which are known protective factors did not necessarily protect children from risk. Moreover, although some internal factors are associated with resilience or non-resilience (e.g., temperament), these too were mediated by environmental influences. Thus, resilience or non-resilience should not be seen as permanent states; they alter as risk and protective factors increase or diminish in the social environment. 


\section{Causal chain effects and turning points}

Rutter (1999: 129) noted that negative experiences tend to cluster and be interrelated:

Empirical findings have increasingly shown that later experiences are not independent of what has occurred before (Rutter and Rutter, 1993). Indeed, it is the existence of long-term indirect negative chain effects that leads to the persistence of the ill-effects of early stress and adversity (Rutter, 1989). 'Bad' experiences are not randomly distributed in the population. There are in fact, huge individual differences in people's exposure to environmental risks (Rutter et al., 1995). The extent of environmental risk exposure is determined in part by societal circumstances but above all it is influenced by how people, themselves behave. By their actions, people do much to shape and select their experiences. In this way, vicious circles build up.

He does, however, show that these causal chain effects can be disrupted by what he called turning point effects. These are mechanisms that may entail 'a degree of redirection of life trajectories' and include (i) those that shut down or open up opportunities (e.g., dropping out of school or persisting with education); (ii) those that involve a lasting change in environment (e.g., geographical relocation; loss of a parent) and (iii) those that have a lasting effect on a person's self concept or expectations of other people (e.g., experience of early abuse or neglect) (Rutter, 1994).

In our longitudinal study, we were able to identify causal chains and turning points in the lives of the children we studied. The power of causal chains to produce predictable effects appeared to be very strong in our participants, many of whose resilient or non-resilient profiles persisted over time. We demonstrate this and the capacity of turning points to sustain or disrupt chain effects in the two case studies that follow.

Rutter (1999: 129) found that chain effects can be environmental or societal in origin (e.g., family break-up $\rightarrow$ less money $\rightarrow$ re-location into less desirable residential location $\rightarrow$ fewer social resources $\rightarrow$ under-resourced school $\rightarrow$ more exposure to risks). He also pointed out that there can be a psychological dimension to these chain effects too-their perpetuation can be influenced by the way people think, behave and act. Our data show that these actions (productive and counterproductive responses to circumstances) are often learnt and sometimes taught. If such learnt behaviours are successful in, for example, temporarily reducing stress or gaining wanted outcomes, then they are likely to recur in similar circumstances. Again, we demonstrate this in our two case studies.

\section{Eight years on}

We terminated the study in 2001 when our subjects were between 14 and 17 years old, having tracked them across the often difficult transition between primary and secondary school. We were encouraged to return to the study in 2005 for a number of reasons, but principally because it is clear that a number of choices present themselves in early adult life, i.e., potential turning points such as choice of life partner, education, and career. Sometimes these may be forced choices (e.g., relocating for work; single motherhood). Another strong motivation to continue was 
that at least 15 of our original participants were still in the area where they had originally been recruited and were easily located via the telephone directory or electoral roll. Of these, six agreed to one last interview.

This final cohort consisted of three males and three females. Two of the females and two of the males had shown behavioural patterns associated with nonresilience that persisted over the five times we interviewed them; one male and one female had shown a consistent pattern of resilient behaviour over that time. The males were aged from 18-21 and the females 16-21. Three were still at school, two were employed part-time and one full-time. We interviewed them using the same protocol that we had used previously (see above).

\section{Two case studies}

Adam and Lydia (pseudonyms) were both 21 years old when we last interviewed them. In their accounts, we examine negative chain reactions that exacerbated nonresilient behaviours, and positive chain reactions that strengthened resilient behaviours. In addition, we identify turning points where crucial decisions were or could have been made to disrupt the flow of chain effects. We also speculate on the role that key institutions in Adam and Lydia's lives (e.g., family, school, work) played in shaping outcomes for them both.

\section{Adam}

When looking at Adam's transcripts over the years, it is clear that various experiences in his everyday life led him to develop many behaviours, attitudes and characteristics associated with non-resilience (low self-esteem, poor sense of selfefficacy, resignation of decision-making to others, victim-hood, few plans for the future) and that these features persisted into adulthood. We will present two negative chain effects that we found in Adam's life that we argue have contributed to this state.

The first chain effect began when Adam was placed in a grade lower than his peers when he moved to a new primary school in the early years.

A: I'm older than most of the Year 8 s because I'm meant to be in Year 9 this year. I had to do 18 months Reception because I moved to Brookbank after 6 months and I had to do Reception again there.

The reason for this placement is unclear but as a consequence he remained older (and physically bigger) than his classmates throughout his primary and secondary schooling. One serious side effect of this was difficulty making friends in his class during the primary years. Those friends he did have were peers from outside school but, being in the next grade, they all left to go to secondary school a year ahead of him. His interview at 13 years of age (a year older than most children in Graded 7 in SA) showed a mutual rejection between Adam and others in his class:

Q: Do you play with your class mates at lunch and recess? 
A: No, they all play soccer. I used to play last year but not any more because most of my friends were Year 7s last year and they all left and I can't really play with the people this year.

Q: Why's that?

A: Because they're ... I don't like them much and they don't like me.

When he finally made the transition to high school, he was of course, still a year older (and thus bigger) than other Year 8 students. Without any real practice in making friends at primary school, he was not very successful at this in the new high school environment. He developed 'out of reality' pursuits (reading, computer games, TV watching) that did not involve interaction with others:

Q: What's good about being Adam at the moment?

A: Not much.

Q: Not much?

A: No. I've got a good family and that.

Q: But you don't feel good about yourself?

A: I suppose I'm out of reality with the time reading books and that.

Q: So, what message are you getting from other people about you?

A: They just don't like me.

Q: So what's the worst thing for you at the moment?

A: Not enough friends.

Q: Isn't there anyone at school you can trust?

A: Some. It's just that they might just ... you know, they might just join in with the popular people because they seem to get more popular by joining in with them. You know how it works.

While Adam appeared to have a clear insight into how popularity in teenage social groups operates, he appeared to be unable to adopt or use strategies to gain acceptance within a peer group at his school. He confided that he wished he had gone to another school where his age-mates from primary school had gone. However, his mother had chosen to send him to his present high school. He regretted this choice because even though these boys were a year ahead of him, he felt that they would have been his friends ('I should have gone to where they went').

In this chain effect, the decision about Adam's placement right at the beginning of primary school had a long-term and cumulative effect on his ability to make and sustain friendships throughout his school career. He developed a negative sense of self-efficacy - he seemed resigned to his loner state and rejection. He did not feel confident enough to employ different social strategies to improve his chances of gaining friends and few people at his school, it seems, saw Adam's social isolation as a problem sufficient to warrant intervention. His retreat into solitary pursuits ensured that he had even fewer opportunities to learn valuable social skills. Yet this strategy can be seen as functional from Adam's point of view. The consequences of social interaction for him were painful and unpleasant and so they 
were not repeated, but avoided. Adam, we argue, learnt to retreat from social involvement.

A second chain effect was very closely interwoven with the first and involved bullying. Adam was different from his class mates in age and size and was teased and bullied at primary school for being overweight ('I'm not very proud of being overweight') although the interviewer's field notes state that Adam was not overweight but was 'sturdily built' and this set him apart from the rest of the boys in the class. Adam was given a hard time. Appeals to the teacher did not seem to provide a permanent solution and again, he seemed resigned to this experience.

A: There's one person I really don't like-actually two.

Q: Why's that?

A: Because they tease me.

Q: What do you do when they tease you?

A: Not much.

Q: You just sort of do nothing?

A: Yeah. I tell the teacher sometimes.

Q: Does that help the situation?

A: Sometimes. It's one, mainly it's only one person that does it. Sometimes some of his friends will join in but not very often.

Predictably, the bullying persisted in high school. Then, it wasn't just one or two boys but a big group who bullied him. Resignation to his fate was encouraged by the lack of teacher intervention and what was perceived to be a failure of the school's anti-bullying program. Although Adam agreed with the interviewer when it was gently pointed out that maybe a new personal strategy to combat bullying was needed, he showed a lack of self-efficacy in responding to this suggestion.

A: I'm a lot taller and I have had quite a few run-ins with people. I don't really bash them up or anything.

Q: Did you pick on them or did they pick on you?

A: They pick on me. They call me fat and that.

Q: Do teachers allow that to happen?

A: If there's a lot of people, what can the teacher do? Let's say the whole class tells that this person didn't do that, well there's nothing the teacher can really say because the whole class says that they didn't do that.

Q: So there's groups—gangs?

A: A big group and everybody likes ... well whoever the bully is, they'll lie for him.

Q: What about going to the school counsellor?

A: People won't quit teasing me anyway and it doesn't matter. You can't really do anything about somebody who just says things and all that. You can't do anything serious like suspend them or anything. So there's nothing really to it, so you just have to ignore it.

Q: So if a kid starts teasing you, how do you react? 
A: Usually ignore them. But that usually makes them angrier.

Q: OK. So, do you think being passive and walking away is the best thing to do?

A: Yeah. Sometimes it is, but if you turn away, usually they hit you in the back or something.

Q: So perhaps you need another strategy?

A: Yeah. There's always one person that thinks they're so tough and always trying to push you around and they've got plenty of friends and they think they can push you around as well.

In this negative chain reaction, Adam's painful social interactions in high school further drove him into solitary pursuits ('I read a lot and I play PlayStation') and even led him to avoid pastimes outside school that involved others ('I'd like to play football and cricket. There are local teams. I don't know. I just don't join them much'). His mother continued to make important decisions for him ('She talked me into doing the IT course at TAFE') which he accepted, further reinforcing his lack of self-efficacy and denying him practice in making plans for the future:

Q: OK. So what are your plans for the future?

A: I might join the Air Force and become an officer. I hope anyway. Or get into business or something like that. I don't know—just do a packing job.

When serious situations occurred over his schoolwork he blamed other students and the school and took no action to redress what he claimed to be a serious injustice over his Year 13 results.

A: I went to Year 13. I was so disappointed. Like, the scores that I had before-my results were so different. Like I had As and Bs before. Then [in Year 13] when I got my results back I got Cs and Ds. It's like-how have they dropped so far? You know, I tried hard all year. I did all the work. I was very shocked.

Q: Did you take it up with them?

A: Yeah, they said that it's possible it was a clerical error. I mean, they said it's highly unlikely that it's a clerical error. It's more likely that my teachers mark too softly or something.

Q: So that was a shock to you?

A: Yeah. And I did a VET course that my school forgot to include in my results. So, I didn't have my SACE. I did good enough at school to get into an Arts degree but they didn't give me my six bonus SACE units from a VET course that I did and that was supposed to make up my SACE but it didn't.

Q: And they wouldn't do this retrospectively?

A: Oh, it was too late really.

After school Adam went to TAFE to pursue a course that he wasn't really interested in and ended up working full-time in a job that bored him. He left that job and took up part-time work with a big national chain store and, in his view, was 'exploited' in a 'dead-end position' that offered no prospect of advancement.

We would argue that Adam's overwhelming lack of self-efficacy, fatalism, and passivity, has been learnt partly through the two negative chain reactions 
outlined here. Lack of success with peers led him to adopt a line of least resistance which then became a learned response to other adverse situations. He learnt to do nothing in response to bullying because there was no follow through in the school's anti-bullying strategy. His mother helped teach him to avoid taking responsibility for himself by making important decisions for him about, for example, the schools he should attend and his post-school career.

But there were turning point opportunities which could have disrupted these negative chain reactions. Many schools claim to have anti-bullying policies; if they were implemented effectively, bullying would be significantly reduced (Smith et al., 2004). Adam's school clearly knew he was being bullied (he claims he told his teachers) but took no action to prevent it. No-one in Adam's life seemed to challenge his victim behaviour and attitudes. No-one, it seems, noticed some very valuable personal skills that Adam demonstrates in his accounts (e.g., helping others, solving complex problems in computer games). If significant others had valued and built on these skills this could have developed a stronger sense of selfworth in Adam; others could have shown how these skills might be usefully used in a wider context (e.g., making friends, figuring out social strategies) leading to a stronger sense of self-efficacy. Opportunities for disrupting negative chain reactions were there but were not recognised and acted on.

At 21 it seems mature reflection has enabled Adam to see some things about his life more clearly:

Q: What advice would you give other young people about life?

A: I'm not going to listen to anybody else about what I should do from now on because I wanted to do what I was happy with and I was persuaded to do IT instead.

And now he is facing a turning point and he has the power to make a choice. He has to decide whether to take up mature age entry at university.

Q: Have you made any enquiries about the courses that you could do?

A: Yes. I've got the 2006 booklet at home and I've been going over it and yeah, I'm just going to ... actually I've got to make a late application. I've got to pay a late fee now don't I?

While it's encouraging to see Adam making resolutions about taking control of his own life and thinking about going to university, he has left himself an escape hatch-it might be too late, he might not be able to afford the late fee. In other words, if he doesn't take up this opportunity, it won't be his fault. His learnt passivity and fatalism may have robbed him of the chance to take up the opportunities afforded by this turning point ${ }^{1}$.

1 Subsequent checks of enrolment records at the University of his choice revealed that Adam did not enrol in 2006 or 2007. 


\section{Lydia}

While Lydia had a difficult childhood and adolescence where she virtually became the defacto mother for four younger siblings, she had experiences that helped her to develop many behaviours, attitudes and characteristics associated with resilience. Despite some very serious adverse events that recently threatened to overwhelm Lydia, we could see her drawing on skills she developed through those early formative experiences to get her life back on track. In Lydia's case, we found two positive chain reactions.

The first chain reaction developed within the context of a large extended family in which many members were heavily involved in playing music and performing in musical groups. From an early age, Lydia learnt to play an instrument and at the age of 13 when we first met her, she had already joined a large community music group and some school music ensembles. She was obviously proud of her musical talent ('I've found something I'm good at').

Juggling her musical interests with a difficult family life also taught her important life skills. When 15 years old, Lydia gave an almost classic definition of resilience; she referred to persistence, self confidence, and a refusal to give up when faced with failure:

Q: What advice would you give to other kids about life do you think?

A: Well I would give advice, if someone was upset I'd tell them if someone told them something that they didn't particularly like I'd say, 'Well just forget about it. Just start again, refresh yourself. Just keep going. If you find a hurdle you've got to try and climb over it. You can't just stop and fall to the ground, so you should keep going no matter what, even if you make a boo-boo.'

Q: You've had to learn to do that yourself I guess haven't you?

A: Yes, in music and at school and everywhere.

Lydia's involvement with the community music group also brought her into contact with many adults who became alternative sources of advice, support and caring when her home life was difficult.

Q: Who are the important people in your life?

A: Some of my friends because they helped me out along the way. Mostly adult friends because I understand them more and they've helped me out and they've taken me out to places and let me have fun.

Q: And how come you have these adult friends?

A: Through music. You meet a lot of friends through music.

Not only did Lydia's music give her life structure and alternative sources of support, at age 15 it gave her a clear plan for the future:

My plan is to go to uni. To become a music teacher and hopefully I might end up in the symphony orchestra and travel around the world. I really want to travel and play my music around the world.

This chain effect is less linear that those we presented for Adam. Nevertheless, being encouraged to learn an instrument and being in a family that 
routinely plays music in public triggered a whole range of valuable protective factors in Lydia's life. The experience of displaying her talent in public had several very positive effects: knowing that she was good at something that set her apart from others; praise for her skill; and using it for the good of others all enhanced her sense of self worth. Practice to maintain and improve her skills taught her persistence which she applied to other areas of her life. Her musical activities put her in contact with a wide and diverse group of caring adults beyond the family, who knowing her circumstances, supported and cared for her and provided her with assistance, respite and advice when necessary. Music structured her plans for the future-a clear indication that she believed she had some control over what she did and what would happen to her. Compared with Adam's future plans, there was no sense of Adam's fatalism ('I don't know ... just do a packing job') in Lydia's confident picture of the road ahead.

The second chain effect in Lydia's life came from a potentially negative situation. Lydia's mother was very ill for several years and was often in hospital for extended periods. As the eldest child, Lydia assumed responsibility for her four younger brothers and sisters. Even in her later school years, when her mother's health improved, Lydia still managed many family tasks and dealt with school and family matters. In effect, Lydia was a surrogate mother during much of her adolescence. While this situation was often burdensome, Lydia's accounts show that this experience helped her develop skills and characteristics that are associated with resilience. She gave many examples of taking control of situations, being selfreliant, and solving problems by seeking advice and assistance. At 15 she reported seeking help from a counsellor:

Q: And what about the way that you solved the problem of stress you were feeling [about her mother's health]? Do you feel good about how you overcame that problem?

L: Well I feel proud of myself that I did actually get up and go to a counsellor and talk about it, because for months before I was like, 'Oh I want to, but I don't want to'. Very nervous.

At 17, she discussed her difficulties with talking to her mother:

I think it was because my mum was in hospital for so long. And I never talked to her, she was always sick and then I just sorted my own problems out. Life in general is not easy, you have to be very patient with people, very patient with yourself and to think thoroughly about things and that if you've got a problem instead of going absolutely ape-shit at everything, just sit down and sort it out straight away, otherwise it's going to grow bigger. So, basically, forget about the bad things, but if you've got a real problem, sort it out and try and look at the good things and be positive and keep your head screwed on most of the time.

The absence of her mother and the subsequent stress that this caused Lydia could well have been the starting point for a negative chain effect. However, at the time Lydia took on the responsibility of looking after the family she had already acquired, through her long musical involvement, the valuable protective factors of self-worth and self-reliance, a wide circle of adult friends, the habit of persistence, the strategy of seeking assistance when necessary, and a set of long-term goals. These stood her in good stead when faced with burdens and responsibilities that, we 
argue, few young people her age would have been able to handle successfully. Instead of setting off a negative chain effect, the difficult family situation seemed to strengthen existing protective factors. Throughout her accounts we see her actively caring for others, being self-reliant, solving problems, seeking assistance from counsellors and trusted adults when things got her down and all the while maintaining her goal of going to university and being a music teacher.

Unfortunately, in recent times, Lydia has suffered some devastating experiences that have threatened to overwhelm her. These have involved a catastrophic family crisis and the break-up of her family, the end of her engagement and the end of her career plans. The timing and the severity of the events led to an emotional breakdown and hospitalisation. Lydia had clearly reached a turning point where her life could take one of two directions-she could accept defeat or she could regroup. In her most recent interview, Lydia told how she is doing the latter; she is picking up the pieces of her life and, in doing so, she is drawing on the resilience skills that she learnt earlier.

When members of her family were putting on Lydia to return to help deal with the aftermath of the family catastrophe, Lydia pursued a course of action which showed considerable self insight and an understanding of her emotional needs:

I was stressed [about the broken engagement] but more stressed about the family situation and I needed a little bit of comfort for what I was going through and it wasn't there. In the end, I turned around and said, 'That's it. I'm 21 this year. I've looked after the family for the last 10 or 11 years. It's time for me to look after myself no matter what's happening', and that's what I told my parents.

At her lowest point, Lydia sought assistance from a friend who saw how desperate she was and got her medical help. This involved hospitalisation and Lydia was subsequently diagnosed as being severely clinically depressed. Despite this, she was adept at analysing her situation, and took control by seeking continuing professional therapeutic support, independent housing and reliance on a trusted friend:

L: I took the next step to get the help I needed ... [Being hospitalised] was really scary but I think it's the best thing that's ever happened to me so far, because I really needed to learn some more skills to deal with stress. I was detained in hospital for two days and I was voluntary for the rest of the week simply because I wanted to set up a support network outside the hospital so when I left I wasn't by myself and end up in hospital again. So I did that and while I was there I signed up for leasing a housing trust apartment; I got a regular therapist every week and I got a psychologist as well, which was good.

Q: You mentioned building a support network, where did that idea come from?

L: Me (laughing)! Because I felt very alone and I didn't like it. So, I wanted to change that and I knew that if I had the support of professionals saying 'Yes, you're doing the right thing' then I can do it. So I know I've got someone to ring if I do fall back into depression and I know that I've got my good friend James for support too.

Lydia knew that her plans for a musical career were in disarray, but she was rebuilding a future which involved career training - not in music but in nursing. 
Music will again feature in her life, though, as she talked about returning to her community music group where she still has many friends.

Lydia has been more fortunate than Adam in the way that institutions have worked to sustain positive chain reactions in her life. Her school gave her opportunities to express and develop her musical talent; it provided trusted counsellors and careers advisors. The community supplied further opportunities for learning and playing music and for using her skills to entertain others; it also provided her with a network of supportive adult friends. When she realised she needed professional help to get her through her difficulties, parts of the medical community acted as a source of strength and support. On the whole, we feel somewhat more optimistic about Lydia's future than Adam's.

\section{Conclusion}

Qualitative longitudinal studies enable researchers to see the working parts of people's lives; they give us rich pictures which flesh out the general patterns revealed by larger, quantitative studies. We would argue that in the present case, we can clearly see how positive and negative chain effects can often have their starting points in random, even accidental events. The responses triggered by these events can be positive or negative for the individual. If the response reduces stress or promotes desirable outcomes then it is likely to be repeated. If this happens often enough, certain ways of behaving (avoiding social situations, practising to develop skills) become part of the individual's behavioural repertoire.

Opportunities for disrupting these sequences come at different times and through different agencies, but schools are clearly an important place where this can happen. While children like Lydia, who are successful, talented, personable and cheerful will often attract the help and support they need, children like Adam often don't. A child who is a social isolate, who is passive and adopts the role of a victim, is often less rewarding to work with. We would argue that there are plenty of things that schools and teachers can do to help disrupt the negative chain effects that bedevil some children.

Certainly, we would argue that resilience and non-resilience are not permanent traits that an individual either has or hasn't got. We believe that these case studies clearly show that resilient and non-resilient behaviours are learnt. In the case of non-resilient behaviours, what has been learnt can be unlearnt and new, more productive ways of dealing with life can be substituted. Schools in particular need to be alert to the fact that they can often disrupt negative chain effects in children's lives and teach new, more constructive ways of behaving. In this way, resilience in the face of adversity can be achieved by a much wider group of children than is currently the case. 


\section{References}

Benard B, 1991, Fostering Resiliency in Kids: Protective Factors in the Family, School and Community. Western Center for Drug-Free Schools and Communities, Portland, Oregon.

Consortium on the School-Based Promotion of Social Competence, 1994, 'The school-based promotion of social competence: Theory, research, practice and policy'. In Haggerty R et al. (eds), Stress, Risk and Resilience in Children and Adolescents: Processes, Mechanisms and Interventions. Cambridge University Press, New York.

Coburn J and Nelson S, 1989, Teachers Do Make A Difference: What Indian Graduates Say About Their School Experience, (Report No. RC-107-103). Office of Educational Research and Improvement, Washington DC, (ERIC Document Reproduction Service No. ED 306 071).

Dryfoos JG, 1990, Adolescents at Risk: Prevalence and Prevention, Oxford University Press, New York.

Garmezy N, 1985, 'Stress resistant children: The search for protective factors'. In Stevenson JE (ed.), Recent Research in Developmental Psychology, Journal of Child Psychology and Psychiatry. (Book Supplement No. 4).

Garmezy N, 1994, 'Reflections and commentary on risk, resilience, and development'. In Haggerty $\mathrm{R}$ et al. (eds), Stress, Risk and Resilience in Children and Adolescents: Processes, Mechanisms and Interventions. Cambridge University Press, New York.

Geary PA, 1988, “"Defying the Odds?”: Academic success among at-risk minority teenagers in an urban high school', (Report No. UD-026-258). Paper presented at the annual meeting of the American Educational Research Association, New Orleans, La. (ERIC Document Reproduction Service No. ED 296 055).

Gore S \& Eckenrode J, 1994, 'Context and process in research on risk and resilience'. In Haggerty R et al. (eds), Stress, Risk and Resilience in Children and Adolescents: Processes, Mechanisms and Interventions. Cambridge University Press, New York.

Hawkins JD, Catalano RF \& Miller J, 1992 'Risk and protective factors for alcohol and other drug problems in adolescence and early adulthood: Implications for substance abuse prevention', Psychological Bulletin , 112, 64-105.

Masten A, Best K \& Garmezy N, 1990, 'Resilience and development: Contributions from the study of children who overcome adversity', Development and Psychopathology, 2, 425-44. 
Pence AR (ed.), 1988, Ecological Research with Children and Families: From Concepts to Methodology, Teachers College Press, New York.

Smith PK, Pepler D \& Rigby K, 2004, Bullying in schools: How successful can interventions be? Cambridge University Press, Cambridge.

Rutter M, 1980, Changing Youth in a Changing Society, Harvard University Press, Cambridge, Mass.

Rutter M, 1987, 'Psychosocial resilience and protective mechanisms', American Journal of Orthopsychiatry, 57, 316-31.

Rutter M, 1994, 'Continuities, transitions and turning points in development'. In Rutter M \& Hale D (eds), Development through life: A handbook for clinicians. Blackwell Science, Oxford.

Rutter M, 1999, Resilience concepts and findings; implications for family therapy, Journal of Family Therapy, 21, 119-44

Rutter M, Maughan B, Mortimore P \& Ouston J, 1979, Fifteen Thousand Hours. Secondary Schools and their Effects on Children. Harvard University Press, Cambridge.

Werner E \& Smith R, 1988, Vulnerable but Invincible: A Longitudinal Study of Resilient Children and Youth, Adams, Bannister and Cox, New York. 